\title{
Habermas, Argumentation Theory, and Science Studies: Toward Interdisciplinary Cooperation $^{1}$
}

\section{WiLliam ReHG}

Saint Louis University

\begin{abstract}
This article examines two approaches to the analysis and critical assessment of scientific argumentation. The first approach employs the discourse theory that Jürgen Habermas has developed on the basis of his theory of communicative action and applied to the areas of politics and law. Using his analysis of law and democracy in his Between Facts and Norms (1996) as a kind of template, I sketch the main steps in a Habermasian discourse theory of science. Difficulties in his approach motivate my proposal of an alternative approach that starts not with a theory of communicative action but with some broad categories drawn from argumentation theory. Using these categories, one can survey the various conceptions of scientific argumentation that have already emerged in the multi-disciplinary field of science studies. The more flexible, open-ended theoretic categories put one in a better position to develop cooperative interdisciplinary studies that can inform the critical assessment of scientific argumentation.
\end{abstract}

Résumé: J'examine deux méthodes pour analyser et évaluer l'argumentation scientifique. La première approche utilise la théorie du discours que Jurgen Habermas érige sur la base de sa propre théorie de l'action communicative qu'il a appliquée surtout au droit et à la politique. Employant comme modèle son analyse du droit et de la démocratie avancée dans le livre Between Facts and Norms, j' énumère les étapes principales du discours scientifique. Confronté avec les problèmes soulevés par cette approche, je propose une alternative qui commence, non pas avec un théorie de l'action de la communication, mais plutôt avec quelques distinctions générales tirées de la théorie de l'argumentation. En faisant appel à ces distinctions, nous pouvons faire un survol des conceptions diverses de l'argumentation scientifique qui ont déjà été proposés dans le champs de la recherche multi-disciplinaire de l'étude de la science. Ceci nous met dans une meilleure position pour développer des études coopératives interdisciplinaires ayant pour but d'évaluer l'argumentation scientifique.

Keywords: Habermas, argumentation, discourse, science studies

\section{Introduction}

Today science has acquired increasing importance in a number of social and politi$\mathrm{cal}$ arenas. From administrative policymakers designing environmental regulations to courts grappling with DNA tests, from legislatures debating hazardous material controls to international bodies negotiating fossil-fuel emission standards, from publics deliberating limits on stem cell research to individuals deciding on cancer detection and treatment, increasingly we find ourselves confronted by questions in which reasonable choices, it seems, require us to assess the relevant scientific 
findings. Presumably such assessment must take the science seriously, albeit with a critical sense of its adequacy and relevance to the question at hand. Thus the various forms and forums of science-related deliberation draw our attention to the discursive side of science - the fact that scientific hypotheses, results, and forecasts must take shape as arguments and find their way in social processes of argumentation. In scrutinizing scientific claims for their relevance and strength, one takes a discriminating critical approach to science-based argumentation-a stance that neither crudely dismisses nor naively accepts what passes for expert authority.

The situation and issues described above provide the broader background and motivation for this essay, which focuses on the more specific question of how best to frame a theoretical approach to the assessment of scientific arguments, which are increasingly relevant for both public deliberation and personal choices. What methodology or heuristic, what questions and concepts, should inform a theoretical approach adequate to the complexity of such assessments? Presumably the approach should be interdisciplinary. Jürgen Habermas's "discourse theory" is one of the more likely candidates. Although worked out primarily for law and democracy, Habermas's discourse theory provides a capacious argumentationtheoretic framework that we might extend to the critical analysis of scientific argumentation. If the extension succeeds, then we would have a model that promises to cover a range of contexts, both inside science and at the boundaries of science and society, in which scientific arguments are relevant. After describing and critically appraising such an extension (sec. 1), I present an alternative in response to weaknesses of the Habermasian approach (sec. 2). I close by briefly sketching two interdisciplinary applications of the alternative approach (sec. 3).

I should note at the outset that in working out the extension of discourse theory and its alternative, I focus primarily on argumentation inside science. I do so partly to keep things manageable. Nonetheless, the intra-scientific domain constitutes an important component of a theoretical approach to the broader issue of science in practical decision-making. In other words, I assume that understanding the merits or cogency of scientific claims in the practical contexts of politics, law, and everyday life requires some understanding of scientific argumentation within science. Indeed, in some cases the unwritten technical details of evidence-assessment can become relevant in legal-political contexts (e.g., Lynch, 2000). Even when the standards for cogent claims within the sciences are not identical with those that govern the use of science in broader social-political contexts, when we consult science in such situations we hope that its representatives (experts, science writers, physicians, etc.) have made an accurate assessment of the current scientific arguments-that is, of the cogency or strength of the available evidence for relevant scientific findings. 


\section{Habermas's discourse theory of law and democracy as a template}

More than forty years after Thomas Kuhn's Structure of Scientific Revolutions (1962; 3rd ed., 1996), we find before us an abundance of options for analyzing scientific argumentation and arguments. Over the course of the last century philosophers of science, concerned above all with the rationality of science, have provided a range of analyses: of inductive inference and confirmation, theoretical structure and explanation, and so on. A growing store of detailed studies of the social constitution of scientific knowledge now challenges and complements these philosophical accounts. The various disciplines - philosophical, historical, literary, and empirical-assembled in the area known as "science studies" offer us a range of perspectives and ideas for understanding scientific argumentation as a social practice, as subject both to normative ideals and contingent social limitations (Biagioli, 1999; Jasanoff et al., 1995).

However, the perspectives and approaches on offer run in diverse, often incompatible and even outright contradictory directions. How then can we acquire a relatively comprehensive understanding of science, one informed by this wealth of information, without falling into incoherence or empty generality?

One model that might offer some clues for answering this question is Habermas's discourse theory of law and democracy (Habermas, 1996). As a "discourse theory", Habermas's account significantly draws on argumentation theory, above all for normative orientation. Yet it does so with the aim of providing a comprehensive, empirically informed yet coherent theory of legitimate lawmaking in contemporary democracies. So perhaps his theory can supply us with a model, or something like a template, for acquiring a comprehensive but manageable understanding of contemporary science and its modes of argumentation. With his democratic theory as our exemplar, we can imagine at least some of the main steps toward a Habermasian "discourse theory of science". After all, in Habermas's architectonic, science like law emerges in modernity as a result of the institutional differentiation of value spheres; like law it represents both a system of cultural knowledge and an institutional complex. In this section, then, I first introduce Habermas's broader discourse theory and the theory of communicative action (TCA) that undergirds it. We can then consider how TCA might extend to scientific discourse and what strengths and weaknesses such an approach exhibits.

\subsection{Communicative action, discourse, and democracy}

As one can gather from his 1962 habilitation on the public sphere (Habermas, 1989), Habermas has been interested in issues connected with the legitimacy and feasibility of constitutional democracy from early in his career. Along with KarlOtto Apel and other members of the postwar generation who were disappointed by the failure of the German academy to resist National Socialism, Habermas looked to Anglo-American sources for theoretical inspiration-in particular to pragmatism and linguistic philosophy (Habermas, 1979; Apel, 1980, 1981). The ma- 
ture expression of these theoretical proclivities appear in his two most extensive monographs, the two-volume Theory of Communicative Action (1984/1987), and Between Facts and Norms (1996). The two-volume work develops a pragmatic theory of language as the framework for approaching issues of social order and modern rationalization; the second work then elaborates the implications of that framework for a normative theory of democratic governance in complex, pluralistic societies.

As I noted above, Habermas's approach recommends itself for a number of reasons - its breadth and flexibility, interdisciplinary openness to relevant empirical work in sociology, political science, linguistics and the like, and use of argumentation theory. Taken together, these features make TCA a promising framework for situating scientific discourse in broader social, political, and legal contexts. Three features in particular deserve attention: the account of validity claims, the theory of discourse (i.e., the argumentation theory), and the proceduralist model of democratic legitimacy.

(1) According to Habermas, stable human association cannot be explained simply in terms of instrumental, or "strategic", modes of interaction in which actors calculate their moves simply on the basis of assumptions about each others' desires and fears (or "preference orderings" in game-theoretic terms). ${ }^{2}$ Rather, ongoing social order also involves, indeed ultimately depends on, richer communicative modes of interaction in which actors raise and accept-or reject, discuss, and revise-claims that have an intersubjective validity based on mutually convincing reasons (or at least on the mutual supposition that such reasons exist). In sharp contrast with the positivist tradition, Habermas does not limit such intersubjectively valid, or justifiable, claims to the category of empirical truth, but instead recognizes a spectrum of "validity claims" that includes, at the least, claims to moral rightness, ethical goodness or authenticity, personal sincerity, and aesthetic value (Habermas, 1984/1987, 1: 8-23; 1993, Chap. 1). ${ }^{3}$

(2) At the core of Habermas's TCA, then, lies the thesis that ongoing social interaction requires actors continually to make and accept validity claims on the supposition that good reasons could, if necessary, be supplied to justify the claims. Consequently, communication contains an implicit reference to argumentation or discourse, the form of communication in which actors put aside the pressures of action in order to critically discuss a validity claim that has become problematic. ${ }^{4}$ The rational basis of communication and social order thus lies in the rationality of discourse as critical discussion: if for example we accept a moral judgment as right, or an empirical claim as true, then we tacitly assume the judgment or claim would hold up in a rational discourse. To spell out the conditions on such discourse, Habermas draws on the work of Robert Alexy (1990; Habermas, 1990, 86-89). But he organizes Alexy's standards according to the familiar tri-dimensional model that analytically distinguishes three aspects of argumentation-product, procedure, and process, which Habermas loosely aligns with the logical, dialectical, and rhetorical perspectives of the Aristotelian canon (Habermas 1984/ 
1987, 1: 22-42; cf. Wenzel, 1979; 1990; Rehg, 1997). In brief, the model implies that good reasons have argumentative cogency insofar as (a) from the logical perspective, they provide sufficiently strong support for the claim at stake, (b) from the dialectical perspective, they can withstand objections, and (c) from the rhetorical perspective, they are persuasive for audiences (of active participants) that are both inclusive and reasonable. Although Habermas (1973) originally spelled out the notion of an inclusive and reasonable audience in terms of the "ideal speech situation", a phrase like "process idealizations" is less misleading. Process standards of inclusiveness, open discussion, and the like articulate counterfactual idealizations that real participants must presuppose they have sufficiently "approximated" insofar as they consider their real discourse to count as rational (Habermas, 1993, 51-57).

(3) Habermas's proposals have provoked numerous criticisms and further questions, but at this point it is more important to notice that the process aspect of argumentation shoulders most of the normative burden in his subsequent claborations of a discourse theory of morality, law, and democracy (Habermas, 1990; 1993; 1996). One reason for this lies in the intersubjective, proceduralist character of his moral-political theory. In that theoretical context, the term "proceduralist" refers to a contrast not with product and process, but with substance. Thus Habermas's discourse ethics is proceduralist in the neo-Kantian sense that it does not set forth a specific list of moral norms but rather gives us a procedure for determining what is right and wrong. However, unlike Kant's moral theory, in which the relevant procedure involves a thought experiment carried out by the single individual, discourse ethics requires actors to engage one another in an aclual discourse-albeit one whose reasonable character warrants a defeasible confidence that the outcome is morally valid, that is, a moral norm or judgment that can be impartially justified to all concerned. In his political theory, Habermas (1996) links legitimacy to the quality of the "democratic procedure" as one that, analogous to moral discourse, fosters legal outcomes that enjoy the presumption of reasonableness and thus should be considered legitimate and binding by all reasonable citizens. ${ }^{5}$ To do justice to the more complicated situation in political discourse, one must conceive the relevant discussion as both broadly decentered (across a range of venues and forums that contribute to the public sphere) and multi-level (inasmuch as broad public discussions should feed into various governmental bodies such that laws, policies, and decisions reflect the broader discussion). Political discourse also exhibits an internal complexity from which Habermas's moral theory abstracts: legitimate political outcomes must take into account not only moral considerations but also the particular cultural self-understandings and traditions in a polity, questions of feasibility, coherence with the particular legal system, and so on.

\subsection{A Habermasian discourse theory of science}

The foregoing sketch should, I hope, give some sense of the breadth and complexity of Habermas's analysis of political legitimacy and its basis in argumentation 
theory. Notice in particular the complex character of political discourse, which involves not only specifically moral argumentation but also what Habermas calls ethical-political discourse (which addresses the questions connected with cultural self-understandings) and legal discourse (which addresses, inter alia, the question of coherence with existing law). A legitimate legal-political outcome would presumably have to satisfy the argumentative standards that govern such sub-discourses. It is not hard to see that Habermas's political theory also calls for a theory of scientific or empirical discourse as a further component, which would become relevant when legal-political decisions call for scientific expertise.

However, to approach scientific discourse simply from the standpoint of political legitimacy considerably attenuates the analysis. Exert opinion has its origin, after all, in a socio-institutional complex whose cultural stature, complexity, and influence-both as a system of institutions and as a body of accepted putative knowledge-lie on a par with the legal-political complex. In both cases, we have a set of institutions and practices specialized for answering certain kinds of questions: in the case of science, questions of empirical truth, in law and politics, practical questions about how to regulate a polity's life in common. Similar to the way that legal-political arguments and procedures should generate legitimate legalpolitical decisions, scientific organizations, research, and arguments are supposed to generate well-justified, reliable empirical conclusions. To ground a deliberativedemocratic analysis of expertise in its point of origin, then, one should have a sufficiently comprehensive understanding of science as a major socio-institutional complex or "value sphere" specialized in the production of empirical knowledge (cf. Schomberg, 2002). Might we not elaborate a discourse theory of science modeled on Habermas's discourse theory of law and democracy? If we follow the main steps in his Between Facts and Norms (1996; hereafter BFN), then the following steps in a discourse theory of science suggest themselves:

(Step 1) To begin with, a Habermasian discourse theory of science would take the theory of communicative action, and the associated account of modernity, as its point of departure. This first step matches the first chapter in $B F N$, albeit now with a focus on the validity sphere of empirical truth, its differentiation from (moral-legal) rightness and (personal and aesthetic) authenticity, and its association with the rise of modern science as a major institution. From an argumentation-theoretic standpoint, this first step explains how a specific kind of claim, namely the claim to truth about the empirically observable world, emerged as a major focal point for certain socio-institutional practices of inquiry and argumentation. The precise analysis of truth raises difficult further questions, but presumably one could settle for a rather broad pragmatic notion that would leave philosophical disputes largely open. ${ }^{6}$ In this first step one would no doubt have to say something about the relationship between science and technology, particularly in view of the growing amalgam known as "technoscience"--science that is inherently bound up with its social applications (technological, medicinal, etc.). 
(Step 2) Taking a cue from the second chapter of $B F N$, one might then insert a dialectical account of the major theoretical understandings of science and its modes of argumentation. Just as Habermas opposes highly normative philosophies of law, such as that of John Rawls, to disenchanted sociological accounts such as Niklas Luhmann's, so also one might notice the opposition between rationalist philosophy of science and relativistic, non-normative sociologies of scientific knowledge (SSK). Whereas rationalists like Carl Hempel (1966) and Larry Laudan (1977) tend to treat science exclusively as a system of generalizable knowledge, SSKers such as David Bloor (1991), Bruno Latour, and Steve Woolgar (Latour and Woolgar, 1986; Latour, 1987) highlight science as a contingent constellation of interestbased alliances, negotiations, institutional dynamics, and the like. As in the case of Habermas's legal-political theory, so also this theoretical opposition sets one of the major tasks for the discourse theory of science, namely to go beyond one-sided models that fail to do justice to both sides of science--science as making rationally justified claims to genuine knowledge and science as subject to socially conditioned contingencies.

(Step 3) In the third step one tackles the above task at an abstract philosophical level. This corresponds to BFN Chapters 3 and 4, Habermas's philosophical reconstruction of the basic elements of democratic legitimacy as a combination of "facticity" and "validity", as a tension between universalistic normative ideals of law and its de facto social contingencies and enforcement. In the area of science studies, we see an analogous tension between the universalistic, normative ideals that are supposed to govern scientific argumentation and various socio-institutional mechanisms (decision-making mechanisms, gate-keeping functions, etc.) that are necessary in view of the scarcity of material resources, time, and the like. At this philosophical level, one would articulate the basic normative concepts, ideals and idealizations, that scientific institutions and practices, at their best, strive to satisfy-the ideas in virtue of which one can legitimate science as a rational, epistemically promising endeavor. As Habermas predicates his reconstruction of law on the goal of establishing a harmonious association of free and equal citizens, so one would have to say something about the core aim or aims of modern science and technoscience, and its institutional organization as a "community" of inquirers.

A plausible account should not assume that science is a "pure" or "valueneutral" search for knowledge (Longino, 1990; Douglas, 2000; Kitcher, 2001). Nonetheless, the starting point in TCA implies that the truth claim lies at the core of such a reconstruction. As already mentioned, we need not understand "truth" here in a metaphysically realist sense- a more pragmatic notion of truth as empirical adequacy suffices to get the analysis going. Nor need we feel too constrained by Habermas's early writings on science and technology as predicated on a human species interest in prediction and control of nature (Habermas, 1971). This interest no doubt drives many areas of science insofar as practitioners and their institutional sponsors envisage technological opportunities and spin-offs. However, I fail 
to see how prediction and control can account for all the sciences (e.g., areas of paleontology) or even for the motivation and self-understanding of many scientists, who see themselves as responding primarily to wonder at the mysteries of the universe.

Like Habermas's philosophy of law, the reconstruction of science should state those abstract, high-level conditions on the pursuit of science as a socio-institutional enterprise oriented toward knowledge of the world. Just as Chapter 3 of $B F N$ deals with citizenship rights, so should the account of science spell out the entry conditions for participation in scientific research and argumentation. Corresponding to Chapter 4, where Habermas outlines the basic constitutional structures that (approximately) realize the legitimating potential of discourse among citizens, an account of scientific discourse would presumably have to lay out the key argumentative structures and concepts that explain the rationality of scientific debate and consensus. We would expect here a philosophical treatment of the process of scientific research and discourse, as it begins with project selection, moves through laboratory experimentation, informal dissemination of results, publication, and ends with reception (or lack thereof) by other scientists. This account would no doubt draw upon the core concepts that have long occupied philosophers of science-conjecture, observation, confirmation, explanation, and so on-but it would situate these ideas in social practices of argumentation oriented toward empirical truth.

(Step 4) In Chapter 5 of BFN Habermas turns from philosophy of law to legal theory proper; that is, the self-reflection of legal scholars on their own particular legal systems-in this case, those of the United States and Germany. Ultimately he has an eye on a debate over the self-understanding of contemporary lawmaking, adjudication, and administration, namely the debate between classical-liberal and welfare-state views, which he links with different "paradigms" of the relation between law and society. Habermas contends that discourse theory offers a third alternative: a proceduralist paradigm of legitimate law. Because these paradigms operate as a set of tacit background assumptions for legal theorizing and adjudication in particular constitutional states, each with its own history and idiosyncrasies, to make his case Habermas must demonstrate the contextual relevance of his abstract discourse theory for real polities. To this end, Chapter 5 aims to show the implications of discourse theory for context-specific legal theory; Chapter 6 further contextualizes the argument by linking it with debates over the roles of the Supreme Court and the German Constitutional Court. Subsequent chapters expand the argument by grappling with the socio-institutional feasibility of democratic deliberation in real contexts conditioned (and typically distorted) by powerful social interests, mass media, citizen apathy, and so on. The argument closes in Chapter 9 with a fuller account of the proposed proceduralist alternative and its superiority.

What do these moves suggest for a critical discourse theory of science? A fairly obvious implication is the general requirement of demonstrating the relevance 
and feasibility of the theory for the current situation--both for the theoretical debates and for the social issues and problems in which scientific arguments have force. But notice that to accomplish this contextualization of discourse theory one must identify the specific - in particular the most important or central-debates and issues of today, just as Habermas construed contemporary debates in legalpolitical theory as a contest of paradigms. For Habermas, the conflict of paradigms touches on the very possibility of legitimate constitutional democracies (see $B F N, 391$ ).

One could make a case, I suggest, that the changing character of science-inrelation-to-society, or what some have dubbed the "contract between science and society", is a topic that merits our close attention today. If so, then a plausible discourse theory of science should speak to the various issues that arise in connection with this "social contract". Here one might take as a starting point the analysis developed by Helga Nowotny and colleagues (Nowotny et al., 2001; Gibbons, 1999), who describe a broad-reaching socio-institutional transition from "Mode 1" to "Mode 2" knowledge-production. The heightened demands of social context on science lie at the heart of their analysis. Mode 1 science assumes an autonomous science, one more or less separated from society and oriented toward "reliable knowledge" validated by experts inside laboratory settings (or more broadly, inside carefully defined and technologically controlled environments). Mode 2 science, by contrast, must be "socially robust", able to prove itself not just inside the lab but outside as well, which is to say, before affected lay publics whose knowledge of local context qualifies them as experts with a voice in shaping scientific research agenda.

To be sure, one might identify somewhat different science-related issues, and different theoretical analyses, as the occasion for contextualizing discourse theory. But the Mode 1/Mode 2 analysis recommends itself-at least as a starting pointfor a number of reasons. For one, the two "modes" lay at the same level of generality as Habermas's paradigms of law. The mode-based analysis also fits with some of his early recommendations for science and technology policy planning (Habermas, 1970, Chaps. 4-5). In particular, the analysis points toward a more democratic approach to science and technology development, and thus could draw upon Habermas's account of deliberative democracy. In any case, if one took this analysis as a starting point, the trick would then be to argue for the practical feasibility of democratized science in contemporary institutional and political contexts. Here one would have to confront the different views on the "public understanding of science" (PUS), which are closely related to the transition from Mode 1 to Mode 2 knowledge-production. As part of a democratic theory, a plausible discourse theory of science would have to identify social and institutional conditions that enable an intelligent lay participation in science and technology policymaking. Although the account would feed into a theory of legitimate legalpolitical decision making, at its core we would expect to find an analysis of the reasonableness, or argumentative cogency, of claims to scientific knowledge, as 
they make their way through diverse arenas of truth-oriented discourse: funding agencies, local laboratory settings, audiences of scientists and technicians, corporate offices, governmental bodies, and lay publics of affected citizens. For each of these arenas, one would have to elaborate conditions for realizable practices of argumentation in which participants and onlookers can make critically informed assessments of the relevance and strength of scientific claims that bear on the various sorts of decisions facing them (political, corporate, personal, etc.). In developing this fourth step-which I admit begs for a closer differentiation than I can provide here-one would strive to bring the philosophical reconstruction to bear on the contemporary situation in a critical-social manner.

\subsection{Critical assessment of the Habermasian model}

How well does a discourse theory of science, as modeled on Habermas's discourse theory of law, address our leading question? That is, how does such a discourse theory help us pull together, or sort through, the diverse initiatives in science studies so as to arrive at a well-informed, comprehensive understanding of scientific argumentation? One way that the Habermasian program helps, indeed one of its chief strengths, lies in its capacity to acknowledge and synthesize the insights of diverse research programs and philosophical perspectives, in such a way that their shortcomings and blind spots can be identified and corrected. The second step in the program announces this synthesizing intention. Thus, in constructing his normative model of legitimacy, Habermas can take seriously the discouraging empirical findings of political sociology (regarding voter apathy, ignorance, etc.), albeit in a way that resists the temptation to reach defeatist or antidemocratic conclusions. One reason he can accomplish this discriminating synthesis lies in his theory of communicative action (step 1 above), whose capacious framework responds to the complexity of social action, and thereby allows one to correct and integrate one-sided philosophical and sociological positions.

A further important resource for this integrative task lies in Habermas's emancipatory vision of democratic self-governance and the rule of law. The orientation toward an expansive vision of social-political life characterizes the tradition of critical social theory from the start: from Marx on, critical theorists have recognized that plausible theorizing depends on some kind of anticipation or projection, however vague or utopian, of a just or emancipated society. A vision of science in society constitutes an important desideratum for a critical discourse theory of science that would bring together different areas of science studies. Without some such vision, the empirically oriented areas of science studies, with their heavy emphasis on detailed case studies, can easily degenerate into a mindless tunneling from one case to the next, with little hint of an overall picture or direction.

However, the capacity of the Habermasian program to sort and synthesize, and in some respects the vision itself, is bound up with the theory of communicative action (and the associated interpretation of modernity) in the first step. Using such a program, one would approach science studies with a particular theory already in 
hand-indeed, a rather ambitious and controversial theory at that. TCA, with its reliance on speech-act theory, its distinctions between strategic and communicative action, system and lifeworld, its typology of discourses, heavily determines further developments in the critical analysis. Consequently, subsequent steps inherit any congenital weaknesses in this first step. And, judging from the critical literature on TCA, problems abound (e.g., Thompson, 1982; Misgeld, 1984; Heath, 2001 ). Most problematic, in my opinion, is Habermas's invocation of a philosophical theory of meaning at the outset of the project. With this initial move, he premises the entire program on his ability to carry the day-or rather, the century-in a protracted technical debate among philosophers of language. This difficulty motivates the alternative I propose.

\section{Argumentation theory as a framework for an interdisciplinary, critical science studies}

If we examine the actual history of theorizing in science studies in the twentieth century (including philosophy of science), we can see that many of the developments-and especially the fields of research that opened up in territories plowed by Thomas Kuhn, Stephen Toulmin, and others at mid-century-focus on science as a process of argumentation. We find the clearest evidence for this claim in the various rhetorics of science that sprouted in soil fertilized by Kuhn's allusions to scientific persuasion. Mainstream philosophers of science have now acknowledged the importance of rhetoric in science as more than mere adjunct or threat. Philip Kitcher (1995), for example, makes the case that even pedestrian reports of laboratory findings involve arguments with rhetorical dimensions. One can now speak of a "rhetorical turn" in science studies without embarrassment; the rhetoric of science has become a recognized area for interdisciplinary work (Klein, 1996, 66-70; see, e.g., Simons, 1990; Krips et al., 1995; Harris, 1997). However, the phrase "argumentative turn" provides a better label for my purposes, ${ }^{7}$ inasmuch as rhetorical analyses have tended to focus on literary features of scientific texts, somewhat to the neglect of logical and dialectical analysis. The proposed argumentation-theoretic framework, though it overlaps with the disciplines involved in the rhetorical turn, shifts the center of gravity of science studies in a normative direction inasmuch as the field of argumentation theory has deep roots in the informal logic and critical thinking movements, rather than in such areas as composition, English, and literary studies. Speaking of the argumentative turn has the further advantage of including a larger range of initiatives and approaches-in particular we can include the logical empiricists, at least in hindsight, as anticipating this turn with their focus on the logic of scientific justification. That is, at least some features of the logical empiricist program we can construe in terms of argumentation theory.

This observation leads to my specific proposal for how we should initially approach the task of a critical discourse theory of science that would pull together the areas of science studies. Although a number of initiatives employ argumenta- 
tion-theoretic ideas, often drawn from the study of rhetoric, most have not attended in any systematic fashion to broader developments in the field of argumentation theory itself. This area of interdisciplinary study has been undergoing a renaissance of its own since mid-century, parallel to the explosion of science studies sparked by Kuhn. These developments, I propose, provide us with a very broad heuristic framework for discerning and organizing the range of perspectives within science studies, albeit without imposing a particular theory of argumentation at the outset. That is, the concepts and questions supplied by the field of argumentation theory allow us to detect the pattern of perspectives and positions that have emerged autochthonously in science studies. Hence the proposal: that we begin the move toward critical science studies by employing argumentation-theoretic concepts and questions as a framework for interdisciplinary engagement.

To come now to specifics, argumentation theorists have become comfortable with two very broad sets of distinctions that can help us sort through the various initiatives in science studies. The first distinction is that between product and process: on the one hand, practices of scientific argumentation generate written or spoken arguments as their products: grant proposals, conference talks, reports, articles. On the other hand, these products issue from certain kinds of social processes and procedures of argumentative inquiry and debate. Although theorists distinguish process from procedure, ambiguities in the latter-more on which momentarily - lead me to lump these together under process. What do I mean by the "process of argumentation"? The burgeoning literature on scientific controversy (e.g., Machamer et al., 2000) provides the clearest examples of argumentative processes, for in controversial contexts scientists generate, criticize, modify and defend conflicting views on some scientific question. But we need not limit process analysis to controversy. Writing a grant proposal requires one to construct an argument, and thus to engage in some kind of argumentative process (Myers, 1990). And the cooperative pursuit of inquiry itself, in which a team of scientists tries out competing hypotheses, can also be studied as an argumentative process (Meiland, 1989). Not that argumentative processes can fully absorb or account for scientific practices: the latter also involve a material substrate of instrumentation and laboratory manipulations, individual reasoning skills and individuals acts of creative insight and discovery. As a social process, argumentation pertains to the ways in which scientists translate such elements into publicly accessible presentations (texts, visuals, etc.) that aim to support publicly credible conclusions.

The second set of distinctions goes back at least to Aristotle, but has been revived by argumentation theorists as a set of perspectives on argumentation, or aspects or dimensions of argumentation, namely the logical, dialectical, and rhetorical (Brockriede, 1982; Wenzel, 1990; Tindale, 1999). Some theorists (e.g., Habermas, 1984, 25-26; Wenzel, 1990) would like to align these with a distinction between product, procedure, and process, but I consider this overly forced; indeed, one can analyze argument products from all three perspectives. Moreover, 
the alignment of dialectic with procedure tends to conflate pragmatic (or idealized) standards of rational debate with institutionalized rules. Hence I would connect the latter with a distinct socio-institutional perspective. The precise understanding of these different perspectives, their interrelationships, and normative standards remains a matter of contention among argumentation theorists, but we need not resolve such issues in order to get started with a critical discourse approach. In fact, if we want to discern the spontaneously emergent patterns in science studies, then we do better to allow science-studies theorists to speak as much as possible for themselves as they flesh out the various possibilities for defining such aspects as scientific dialectics, rhetoric, and so on.

Thus, the first step of the alternative project I propose differs from Habermas's approach in that we do not start by demonstrating the philosophical superiority of a particular theory of argumentation, but rather we simply employ the foregoing framework as a heuristic for sorting out the various ways that science scholars have analyzed scientific argumentation and arguments. In some cases the theorist explicitly labels his or her model as "dialectical," or "rhetorical" (e.g., Pera, 1994; Prelli, 1989; Gross, 1990); in others we must make an assignment ourselves based on the fit between substantive features of the model and general usage (e.g., Kitcher, 1993 tacitly takes a dialectical approach). One can usually discriminate productfrom process-analyses in view of the substance of the model, although some analyses blur the boundaries. In sorting through the various models, one should avoid forcing idiosyncratic models into predetermined boxes; better in such cases to expand the horizon of possibilities by allowing each position to speak for itself, albeit to the specific questions implicit in the argumentation-theoretic framework.

We might view this first step as a kind of meta-theoretical methodology: a heuristically guided description of the field of models and perspectives on scientific discourse. Although we start with a rather simple framework-essentially a two-by-four grid defined by product-process foci and the four perspectivesactually working through the various initiatives reveals a more complicated picture. Boundaries blur, substantively similar models come with different argumentation-theoretic labels, unanticipated hybrids and innovations emerge. As a result, the actual theorizing in science studies forces us to go beyond textbook generalities and to think through the categories of argumentation theory that apply to the assessment of scientific discourse.

The second step takes up the challenge of interdisciplinarity. Science studies scholars (or, more broadly, students of science, technology, and society, STS) still appear less than fully satisfied with the interdisciplinary quality of their work (e.g., Couzzens, 2001; Fuller, 1993). Thus in this second step we clarify the possibilities and obstacles for cooperation between the different models and initiatives laid out in the first step. In some cases, different approaches will be complementary, in others deeply oppositional in their basic philosophical commitments. In still other cases, we encounter quibbles over the details-for example, over how one ought precisely to elaborate dialectical standards, or to distinguish dialectics from rhetoric, and so on. 
Having clarified challenges and opportunities, one might follow a number of subsequent routes. For example, one might try to group together sets of philosophically and methodologically compatible approaches. In the end, however, one must engage in the interdisciplinary project from within one's own theoretical perspective and approach. Thus for the third step one does better, I think, to climb down from the meta-theoretical heights and explore interdisciplinary opportunities at ground level, from the standpoint of one's specific position. So long as we remain above the fray, at a meta-level, we are simply sorting out viewpoints but never taking a specific stance ourselves. In saying this, I assume that the field of science studies does not, in the end, converge on a single comprehensive theory that resolves all the theoretical and methodological conflicts. If we simply survey and chart various conflicts and alliances, then we never arrive at a position with sufficient critical definition to enable us to assess the relevance and strength of scientific claims.

One must, in other words, enter the fray of contention, staking out one's basic theoretical and practical commitments vis-à-vis the current situations and problems that involve science and that call for discourse. This requires in turn that one have (1) some sense of the most pressing and important problem situations one hopes to address, (2) a suitable vision of science and its relation to society, and (3) some idea about how to analyze and appraise scientific argumentation at the level of details, where one must more precisely specify a conception of dialectics in relation to rhetoric, identify critical standards, say something about their application, and so on.

The interest in interdisciplinarity, however, shapes the manner in which one pursues these questions and develops one's commitments. The idea is not so much to construct a theory that can win the day against other theories as to elaborate a range of cooperative projects with other positions on the field-alliances and collaborations that are available for one's approach vis-à-vis alternative approaches. To accomplish this one must have a sufficient sense of one's own theoretical standpoint and its limitations, as well as a willingness to meet other positions halfway insofar as one can enlist them in one's own critical program. If we view the field of science (and technology) studies as ultimately a practical endeavor, oriented toward socially and politically relevant models of the complex interactions that link science, technology, and society today, then in a certain sense we're all in the same boat, arguing about the three considerations listed in the preceding paragraph: about which problems deserve primary attention, about the overall direction of science and technology, and about the finer details of how to develop and criticize cogent scientific arguments and robust knowledge-claims. At the ground level of science studies as an interdisciplinary argumentation theory, the various approaches, including that of the critical discourse theorist, are themselves engaged in a process of argumentation at once agonistic and cooperative. Agonistic insofar as participants disagree and know they disagree, cooperative insofar as they take such disagreements not as an excuse for mutual dismissal, but 
as challenges to find creative possibilities for collaboration and exchange (even if only limited or opportunistic).

We might think of this combination of agonism and cooperation as involving two distinct modes of argumentation. On the one hand, to develop plausible responses to the three issues one must critically evaluate the range of initiatives in science studies for their strengths and weaknesses, and one must argue for and against different models - the agonistic mode, or what Steve Fuller (1993) has associated with the dialectical side of interdisciplinarity. Inasmuch as one must employ this more critical, discriminating approach in defining one's own stance, it constitutes the third step. On the other hand, the aims of interdisciplinary exchange and collaboration give rise to a more constructive, dialogical mode of argumentation (which Fuller links with rhetoric as the art of forging apt partnerships at the propitious moment). Thus, in the fourth step one aims not so much to destroy opponents or reduce them to silence as to enlist them as allies in the critical project, even if only temporarily and for limited purposes. For this mode of argumentation, one's theoretical position counts as stronger, as based on the better argument, insofar as it allows for a greater range of collaborative endeavors without compromising the basic integrity of one's critical project.

Here we can distinguish between at least two levels of interdisciplinary engagement. The easier, and more time-honored among philosophers, we might call "unilateral": one simply appropriates findings and ideas from other fields of study and incorporates them into one's own approach. More challenging is the multilateral interdisciplinary cooperation that involves collaborative projects of one sort or another, from discussion groups and multi-disciplinary conferences, through occasional consultations and joint papers, to interdisciplinary research teams with an ongoing shared agenda that reshapes the self-understanding of the member disciplines (see Klein, 1996).

Interdisciplinary cooperation in this fourth step can generate surprising convergences, in which otherwise conflicting approaches mutually accommodate one another. In some cases, the accommodation simply involves a bracketing of philosophical differences for purposes of the collaboration. In other cases, it can provoke theoretical adjustments within the participating approaches, innovations that would not have occurred were it not for the challenge presented by the other approach. 1 close with an example of each type of case. An example of collaboration based on mutual bracketing involves that between critical social theory and the sociology of knowledge (Rehg, 2000); the case of internal innovation involves critical theory and ethnomethodology (Rehg, 2001).

These cases point to yet a fifth step in the project, in which specific theoretical proposals issuing from interdisciplinary engagement are tested in practice-is, tested through their uptake by the participants themselves in the area to which the proposal is intended to apply. In this step one moves from the level of theorists of science, who reflect on standards of cogency for specific discursive contexts and domains, to the level of the practitioners themselves, the scientists, politicians, 
policy-makers, citizens, and the like who conduct scientific inquiries, make recommendations to administrators, debate policy options and laws, make judgments and reach legally recognized decisions. The adequacy of theoretical analyses of argumentative cogency is determined, at least in part, by their resonance with those for whom they should be relevant (cf. Fuller, 1993, xv).

\section{Two examples of interdisciplinary cooperation}

Critical Theory and the Strong Program. The style of critical theory that has followed in the footsteps of second-generation Frankfurt School theorists Karl-Otto Apel and Jürgen Habermas operates with a rather strong conception of discursive reason, predicated on the confidence that (1) participants in argumentation can respond insightfully to the intrinsic force of reasons, ${ }^{8}(2)$ in such a way that consensus that results from discourse has a context-transcending reach. Thus the Strong Program in the Sociology of Scientific Knowledge proposed by Edinburgh School theorists such as David Bloor (1991; cf. Barnes, 1994) and others represents a particularly challenging test case for interdisciplinary cooperation, inasmuch as they reject the idea of an intrinsic argumentative force that could ground context-transcending truth claims (see McCarthy, 1988). For critical theorists like Habermas, intrinsic force functions more as an idealized posit than a directly perceptible impact, inasmuch as participants always offer and weigh reasons in particular socio-institutional contexts in which any number of other social-psychological influences are also at work. But critical theorists hold that our practices of argumentation presuppose a belief in something like the intrinsic force of reasons as a source of normativity. At least in their more skeptical moods, Strong Programmers reject such force as epiphenomenal: "epistemic factors" reduce in the end to "social factors", such as class interests (see Bloor, 1984). To draw an analogy with religious faith, critical theorists are something like negative theologians, whereas Strong Programmers are "justificational atheists".

Cooperation nonetheless is possible insofar as both camps (1) temporarily set aside the broad philosophical claims connected with their views of argumentative justification, so that they can (2) focus their cooperative analyses on specific cases of scientific argumentation and controversy. SSK skepticism is most interesting when one can show, by a detailed and convincing sociological study, that social interests had a decisive influence on the substance of a particular scientific consensus. Such a possibility in particular cases is not ruled out by anything in the critical theorist's commitment to the intrinsic force of arguments-indeed, Frankfurt School Critical Theory cut its teeth on identifying the substantive influence of capitalist interests on science and technology. At the same time, Strong Programmers do not deny that reasons have an apparent force for participants in a given social context. Thus both theoretical camps can approach cases of scientific argumentation in a way that takes the arguments seriously as the participants perceive those arguments and assess their force; and neither side needs to affirm or deny an 
intrinsic force beyond what the participants (and we theorists) perceive-in-context.

For the critical theorist such an interdisciplinary exercise figures into a critical assessment of a scientific claim on which some group of scientists agrees and which might have social policy implications. The Strong Programmer's ability to identify influential social conditioning of such a claim, for example its dependence on particular social interests, raises the further question of whether such conditioning should undermine the epistemic status of the claim. How one answers that question depends on the specific nature of the social conditioning, its role in generating consensus, and what one takes to be the goal of science in the given area of research. One need not assume a rigid split here between social and epistemic factors, external and internal histories. Helen Longino's suggestive analysis of behavioral biology shows how social goals (pertaining to the social status of women) could plausibly affect the substance of scientific theorizing in such a way that the associated scientific claims would not be undermined (Longino, 1990, Chap. 7; Rehg, 2000, 41-44).

Critical Theory and ethnomethodology. The second example is one in which the two partners in research do not bracket their conflicting background assumptions but modify them so as to arrive at a new theoretical model. Start, again, with the kind of critical theory described above. According to that approach, we can define the intrinsic force of arguments in terms of idealized presuppositions of rational discourse, which we in turn articulate as a set of normative presumptions about the conditions under which rational argumentation should proceed. These presumptions generally take the form of very demanding generalities: that the discourse should be open to every competent person, each of whom is given an equal opportunity to participate, is not subject to any sort of internal or external coercion, and so on (Alexy, 1990). Ethnomethodologists-sociologists who take Harold Garfinkel's studies to heart-have made convincing critiques of the attempt to capture the norms for rational interaction in terms of theoretical generalizations (Bogen, 1999; Lynch, 1993; Garfinkel, 1967). Given the difficulties that attend the attempt to put discursive idealizations to work-a difficulty that even theorists sympathetic to Habermas have noted (e.g., Blaug, 1999)-critical theorists have reason to take the ethnomethodological critique seriously (see Hoy and McCarthy, 1994, Chap. 3). The upshot is that critical theorists, when they articulate discursive idealizations, should recognize the ineliminable contextual (or indexical) character of their idealizations, which is to say: recognize that the relevance and force of generalizing theoretical articulations depend on whether, and how, engaged participants make use of the theoretical ideals in actual processes of discourse. ${ }^{9}$

However, ethnomethodologists also insist on a strict policy of "indifference" that prohibits ethnomethodological observers from imposing their own models or theories of rationality on the interactions and human subjects they study (Lynch, 1997). This policy goes together with a radically anti-theoretical stance-"indifferent" ethnomethodologists always allow the participants they study to lead the 
way regarding the norms of rationality. Drawing upon the pretheoretical interactive competences they share with their subjects of study, ethnomethodologists perspicuously describe the endogenous, local rationalities people actually employbut typically do not notice or advert to-in their production of social order. Consequently, ethnomethodologists must always work up their methods and "theories" of rationality afresh for each case study.

The trick for critical theorists hoping to collaborate with ethnomethodologists, then, is to acknowledge the contextualist critique of generalizing, abstract argumentative norms without thereby renouncing their critical perspective and aims altogether-their ability to criticize a particular socio-institutional context and its assumptions. To pull this off, critical theorists must adopt, not the stance of indifferent ethnomethodological observers, but rather that of participants who are at once ethnomethodologically informed and critically engaged. Like other engaged participants, critical theorists are not indifferent but enter discourse with normative ideas of their own, specifically with normative models of discourse-with argumentation theories, albeit informed by ethnomethodology. As theorists, however, their engagement is probably better described as "vicarious", or indirect, inasmuch as their influence on actual discourses depends on directly engaged participants picking up and actually employing the normative models of discourse that critical theorists have proposed (Rehg, 2002). Thus the attempt to engage with ethnomethodology leads the critical argumentation theorist directly into the fifth step of the project described in section 3 above. As vicariously engaged, critical theorists recognize their position as theoreticians, which limits their time and energy for more direct modes of political engagement (say as a public intellectual or an active member of a social movement). Finally, to avoid a narrow contextualism that would collapse into a mere parochialism, the vicarious engagement of critical theorists must be informed by a broader social vision. With firstgeneration Frankfurt School theorists such as Herbert Marcuse, this vision had had a utopian character. But more realistic or sober visions are also possible.

These two examples do not by any means exhaust the possibilities for interdisciplinary cooperation between critical theorists and other disciplines. However, the two examples 1 have briefly sketched represent two of the more challenging cases of cooperation, given the deep differences in philosophical assumptions held by each side. If cooperation is possible in such cases, then it should also promise to succeed when the parties are not so divided at the philosophical level. If so, then the prospects are good for an interdisciplinary critical science studies based on argumentation theory. 


\section{Notes}

'I thank William Keith, James Collier, Hans Radder, and an anonymous referee for Informal Logic for their comments on earlier versions of this paper, which were presented at the Tenth Annual Critical Theory Roundtable, Saint Louis University (St. Louis, Missouri. Oct. 25-27, 2002) and in a panel session at the Society for Social Studies of Science (Milwaukee, Wisconsin, Nov. 7-9, 2002). I also thank Steve Fuller for joining the 4S panel session (along with Keith and Collier) and for feedback from audience members at these two conferences.

${ }^{2}$ For support for Habermas's thesis from a survey of garne-theory research, see Heath (2001, Chaps. 2-4).

${ }^{3}$ In this context, the term "validity" does not have the specific meaning it has in formal logic, that is, it does not refer simply to the truth-preserving structure of an argument; rather, the phrase "validity claim", as a translation of the German term Geltungsanspruch, refers to the broader idea that a claim (statement) merits the addressee's acceptance because it is justified or true in some sense, which can vary according to the sphere of validity and dialogical context.

"Thus we can align Habermas's discourse theory with the dialectical tradition in argumentation theory, which focuses on dialogue as critical discussion, though much work remains in spelling out the similarities and differences ( $c$. Walton, 1992; 1998; van Eemeren and Grootendorst, 1992).

${ }^{5}$ Habermas's political theory is part of the broader theoretical trend oriented by the idea of "deliberative democracy" (see Bohman and Rehg, 1997; Elster, 1998).

"Note that Habermas (2003) now rejects his earlier consensus theory of truth for a pragmatic realism.

${ }^{7}$ This term is used by Fischer and Forester (1993).

${ }^{8}$ Habermas (1984/1987,1:25) writes that, from the logical perspective, argumentation "has as its aim to produce cogent arguments that are convincing in virtue of their intrinsic properties".

${ }^{3}$ P. A. Cramer's "The Public Metonym" (Informal Logic, this volume) makes a very similar point, albeit from the standpoint of rhetorical analysis.

\section{References}

Alexy, Robert. (1990). A Theory of Practical Discourse. In S. Benhabib and F. Dallmayr (Eds.), The Communicative Ethics Controversy, (pp. 151-190). Cambridge: MIT Press.

Apel, Karl-Otto. (1980). Towards a Transformation of Philosophy (G. Adey and D. Frisby, Trans.). London: Routledge.

Apel, Karl-Otto. (1981). Charles S. Peirce: From Pragmatism to Pragmaticism (J. M. Krois, Trans.). Amherst: University of Massachusetts Press.

Barnes, Barry. (1994). How Not To Do the Sociology of Knowledge. In A. Megill (Ed.), Rethinking Objectivity (pp. 21-35). Durham: Duke University Press.

Biagioli, Mario (Ed.). (1999). The Science Studies Reader. New York: Routledge.

Blaug, Ricardo. (1999). Democracy, Real and Ideal. Albany: SUNY Press.

Bloor, David. (1984). The Sociology of Reasons: Or Why "Epistemic Factors" Are Really "Social Factors". In J. R. Brown (Ed.), Scientific Rationality, (pp. 295-324). Dordrecht: Reidel.

Bloor, David. (1991). Knowledge and Social Imagery. $2^{\text {nd }}$ ed. Chicago: University of Chicago Press.

Bogen, David. (1999). Order without Rules. Albany: SUNY Press. 
Bohman, James, and William Rehg (Eds.). (1997). Deliberative Democracy: Essays on Reason and Politics. Cambridge, MA: MIT Press.

Brockriede, Wayne. (1982). Arguing about Human Understanding. Communication Monographs, 49, 137-147.

Cozzens, Susan E. (2001). Making Disciplines Disappear in STS. In S. H. Cutcliffe and C. Mitcham (Eds.), Visions of STS, (pp. 51-64). Albany: SUNY Press.

Douglas, Heather. (2000). Inductive Risk and Values in Science. Philosophy of Science, 67, 559-579.

Elster, Jon (Ed.). (1998). Deliberative Democracy. Cambridge: Cambridge University Press.

Eemeren, Frans H. van, and Rob Grootendorst. (1992). Argumentation, Communication, and Fallacies. Hillsdale, NJ: Erlbaum.

Fischer, F., and J. Forester (Eds.). (1993). The Argumentative Turn in Policy Analysis and Planning. Durham: Duke University Press.

Fuller, Steve. (1993). Philosophy, Rhetoric, and the End of Knowledge. Madison: University of Wisconsin Press.

Garfinkel, Harold. (1967). Studies in Ethnomethodology. Englewood Cliffs, NJ: PrenticeHall.

Gibbons, Michael. (1999). Science's New Contract with Society. Nature, 402 (December 2, 1999, supplement), C81-C84.

Gross, Alan G. (1990). The Rhetoric of Science. Cambridge: Harvard University Press.

Habermas, Jürgen. (1970). Toward a Rational Society (J. J. Shapiro, Trans.). Boston: Beacon.

Habermas, Jürgen. (1971). Knowledge and Human Interests (J. J. Shapiro, Trans.). Boston: Beacon.

Habermas, Jürgen. (1973). Wahrheitstheorien. In H. Fahrenbach (Ed.), Wirklichkeit und Reflexion (pp. 211-265). Pfullingen: Neske.

Habermas, Jürgen. (1979). Communication and the Evolution of Society (Trans. T. McCarthy). Boston: Beacon.

Habermas, Jügen. (1984/1987). The Theory of Communicative Action (T. McCarthy, Trans.). 2 vols. Boston: Beacon.

Habermas, Jürgen. (1989). The Structural Transformation of the Public Sphere (T. Burger and F. Lawrence, Trans.). Cambridge: MIT Press.

Habermas, Jürgen. (1990). Moral Consciousness and Communicative Action (C. Lenhardt and S. W. Nicholsen, Trans.). Cambridge: MIT Press.

Habermas, Jürgen. (1993). Justification and Application (C. P. Cronin, Trans). Cambridge: MIT Press.

Habermas, Jürgen. (1996). Between Facts and Norms (W. Rehg, Trans.), Cambridge: MIT Press.

Habermas, Jürgen. (2003). Truth and Justification (B. Fultner, Trans.). Cambridge: MIT Press.

Harris, Randy Allen (Ed.). (1997). Landmark Essays on Rhetoric of Science. Mahwah, $\mathrm{NJ}$ : Hermagoras-Erlbaum. 
Heath, Joseph. (2001). Communicative Action and Rational Choice. Cambridge: MIT Press.

Hempel, Carl G. (1966). Philosophy of Natural Science. Englewood Cliffs, NJ: PrenticeHall.

Hoy, David Couzens, and Thomas McCarthy. (1994). Critical Theory. Oxford: Blackwell. Jasanoff, Sheila, Gerald E. Markle, James C. Petersen, and Trevor Pinch (Eds.). (1995). Handbook of Science and Technology Studies. Thousand Oaks, CA: Sage.

Kitcher, Philip. (1993). The Advancement of Science. Oxford: Oxford University Press.

Kitcher, Philip. (1995). The Cognitive Functions of Scientific Rhetoric. See Krips et al. $(1995,47-66)$.

Kitcher, Philip. (2001). Science, Truth, and Demacracy. Oxford: Oxford University Press.

Klein, Julie Thompson. (1996). Crossing Boundaries. Charlottesburg: University Press of Virginia.

Krips, Henry, J. E. McGuire, and Trevor Melia (Eds.). (1995). Science, Reason, and Rhetoric. Pittsburgh: University of Pittsburgh Press.

Kuhn, Thomas S. (1996). The Structure of Scientific Revolutions. $3^{\text {rd }}$ ed. Chicago: University of Chicago Press.

Latour, Bruno. (1987). Science in Action. Cambridge: Harvard University Press.

Latour, Bruno, and Steve Woolgar. (1986). Laboratory Life. $2^{\text {nd }}$ ed. Princeton: Princeton University Press.

Laudan, Larry. (1977). Progress and Its Problems. Berkeley: University of Califomia Press.

Longino, Helen. (1990). Science as Social Knowledge. Princeton: Princeton University Press.

Lynch, Michael. (1993). Scientific Practice and Ordinary Action. New York: Cambridge University Press.

Lynch, Michael. (1997). Ethnomethodology without Indifference. Human Studies, 20, 371-376.

Lynch, Michael. (2000). The Discourse of Courtroom Science: An Ethnomethodological View. Paper presented at the Conference on Studies of Work, Technology, and Practice. Harvard University, May 5, 2000.

Machamer, Peter, Marcello Pera, and Aristides Baltas (Eds.). (2000). Scientific Controversies. New York: Oxford.

McCarthy, Thomas. (1988). Scientific Rationality and the "Strong Program" in the Sociology of Knowledge. In E. McMullin (Ed.), Construction and Constraint (pp. 7595). Notre Dame: University of Notre Dame Press.

Meiland, Jack W. (1989). Argument as Inquiry and Argument as Persuasion. Argumentation, 3, 185-196.

Misgeld, Dieter. (1984). Critical Theory and Sociological Theory. Philosophy of the Social Sciences, 14, 97-105.

Myers, Greg. (1990). Writing Biology. Madison: University of Wisconsin Press.

Nowotny, Helga, Peter Scott, and Michael Gibbons. (2001). Re-Thinking Science. Cambridge, UK: Polity. 
Pera, Marcello. (1994). The Discourses of Science (C. Botsford, Trans.). Chicago: University of Chicago Press.

Prelli, Lawrence J. (1989). A Rhetoric of Science. Columbia, SC: University of South Carolina Press.

Rehg, William. (1997). Reason and Rhetoric in Habermas's Theory of Argumentation. In W. Jost and M. J. Hyde (Eds.), Rhetoric and Hermeneutics in Our Time (pp. 358377). New Haven: Yale University Press.

Rehg, William. (2000). Critical Science Studies as Argumentation Theory: Who's Afraid of SSK? Philosophy of the Social Sciences, 30, 33-48.

Rehg, William. (2001). Adjusting the Pragmatic Turn: Ethnomethodology and Critical Argumentation Theory. In W. Rehg and J. Bohman (Eds.), Pluralism and the Pragmatic Turn (pp. 115-143). Cambridge, MA: MIT Press.

Rehg, William. (2002). The Argumentation Theorist in Deliberative Democracy. Controversia, 1 (1), 18-42.

Schomberg, René vom. (2002). The Erosion of Our Value Spheres: The Ways in Which Society Copes with Scientific, Moral, and Ethical Uncertainty. In R. vom Schomberg and K. Baynes (Eds.), Discourse and Democracy (pp. 219-238). Albany: SUNY Press.

Simons, Herbert W (Ed.). (1990). The Rhetorical Turn. Chicago: University of Chicago Press.

Thompson, John B. (1982). Universal Pragmatics. In J. B. Thompson and D. Held (Eds.), Habermas: Critical Debates (pp. 116-133). Cambridge, MA: MIT Press.

Tindale, Christopher W. (1999). Acts of Arguing. Albany: SUNY Press.

Toulmin, Stephen E. (1958). The Uses of Argument. Cambridge: Cambridge University Press.

Walton, Douglas N. (1992). Types of Dialogue, Dialectical Shifts and Fallacies. In E. H. van Eemeren and R. Grootendorst (Eds.), Argumentation Illuminated (pp. 133-147). Amsterdam: Sic-Sat.

Walton, Douglas N. (1998). The New Dialectic. Toronto: University of Toronto Press.

Wenzel, Joseph. (1979). Jürgen Habermas and the Dialectical Perspective on Argumentation. Journal of the American Forensic Association, 16, 83-94.

Wenzel, Joseph. (1990). Three Perspectives on Argumentation. In R. Trapp and J. Schuetz (Eds.), Perspectives on Argumentation: Essays in Honor of Wayne Brockriede (pp. 9-26). Prospect Heights, IL: Waveland.

William Rehg

Department of Philosophy

Saint Louis University

3800 Lindell Blvd.

St. Louis, MO 63108-3414

USA

email: rehgsp@sluedu 